\title{
COL1A1: A potential therapeutic target for colorectal cancer expressing wild-type or mutant KRAS
}

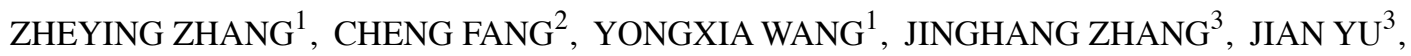 \\ YONGXI ZHANG ${ }^{4}$, XIANWEI WANG ${ }^{5}$ and JIATENG ZHONG ${ }^{1,6}$
}

\begin{abstract}
${ }^{1}$ Department of Pathology, Xinxiang Medical University, Xinxiang, Henan 453003; ${ }^{2}$ Department of Anesthesiology, The Third Affiliated Hospital of Xinxiang Medical University, Xinxiang, Henan 453100; ${ }^{3}$ Department of Pathology, The First Affiliated Hospital of Xinxiang Medical University, Xinxiang, Henan 453003; ${ }^{4}$ Department of Oncology,

The Third Affiliated Hospital of Xinxiang Medical University, Xinxiang, Henan 453100; ${ }^{5}$ Henan Key Laboratory of Medical Tissue Regeneration, Xinxiang Medical University, Xinxiang, Henan 453003; ${ }^{6}$ Collaborative Innovation Center of Molecular Diagnosis and Laboratory Medicine in Henan Province, School of Laboratory Medicine, Xinxiang Medical University, Xinxiang, Henan 453003, P.R. China
\end{abstract}

Received March 13, 2018; Accepted June 8, 2018

DOI: $10.3892 /$ ijo.2018.4536

\begin{abstract}
Colorectal cancer (CRC) treatment primarily relies on chemotherapy along with surgery, radiotherapy and, more recently, targeted therapy at the late stages. However, chemotherapeutic drugs have high cytotoxicity, and the similarity between the effects of these drugs on cancerous and healthy cells limits their wider use in clinical settings. Targeted monoclonal antibody treatment may compensate for this deficiency. Epidermal growth factor receptor (EGFR)-targeted drugs have a positive effect on CRC with intact KRAS proto-oncogene GTPase (KRAS or KRAS ${ }^{\mathrm{WT}}$ ), but may be ineffective or harmful in patients with KRAS mutations (KRAS ${ }^{\mathrm{MUT}}$ ). Therefore, it is important to identify drug target genes that are uniformly effective with regards to KRAS ${ }^{\mathrm{WT}}$ and KRAS $^{\mathrm{MUT}}$ CRC. The present study performed gene expression analysis, and identified 294 genes upregulated in $\mathrm{KRAS}^{\mathrm{WT}}$ and KRAS $^{\text {MUT }}$ CRC samples. Collagen type I $\alpha 1$ (COL1A1) was identified as the hub gene through STRING and Cytoscape analyses. Consistent with results obtained from Oncomine, a cancer microarray database and web-based data-mining platform, it was demonstrated that the expression of COL1A1 was significantly upregulated in CRC tissues and cell lines
\end{abstract}

Correspondence to: Professor Xianwei Wang, Henan Key Laboratory of Medical Tissue Regeneration, Xinxiang Medical University, 601 Jinsui Road, Xinxiang, Henan 453003, P.R. China E-mail: wangxianwei1116@126.com

Professor Jiateng Zhong, Department of Pathology, Xinxiang Medical University, 601 Jinsui Road, Xinxiang, Henan 453003, P.R. China E-mail: zhongjiatengxxmu@163.com

Key words: colorectal cancer, collagen type I $\alpha$ 1, bioinformatics analysis, microarray, KRAS proto-oncogene GTPase regardless of KRAS status. Inhibition of COL1A1 in KRAS ${ }^{\mathrm{WT}}$ and KRAS ${ }^{\mathrm{MUT}}$ CRC cell lines significantly decreased cell proliferation and invasion. In addition, increased COL1A1 expression in CRC was significantly associated with serosal invasion, lymph metastases and hematogenous metastases. Taken together, the findings of the present study indicated that COL1A1 may serve as a candidate diagnostic biomarker and a promising therapeutic target for CRC.

\section{Introduction}

Colorectal cancer (CRC) is the third most common cancer type and the fourth leading cause of cancer-associated mortality worldwide (1). In 2012, there were $\sim 1.36$ million cases and 0.7 million mortalities worldwide (2). CRC may be staged according to the American Joint Committee of Cancer tumor node metastasis or Dukes staging system $(3,4)$. Dukes A/B and UICC I/II are considered early-stage CRC, Dukes C/D and UICC III/IV are considered late-stage CRC (5). Surgical removal is the optimal treatment choice for CRC when detected early, but is often diagnosed too late, whereby the only feasible treatment option left is drugs. Cetuximab and bevacizumab exhibit therapeutic effects on CRC, but the treatment mechanisms are different. Cetuximab is an epidermal growth factor receptor (EGFR) monoclonal antibody and bevacizumab is a vascular endothelial growth factor receptor (VEGFR) monoclonal antibody. Clinically, EGFR monoclonal antibodies are considered if the VEGRF expression level of the patient is low. Thus, the present study focused on EGFR-targeted therapy in CRC $(6,7)$. It has been reported that EGFR-targeted drugs exhibit a positive effect on KRAS proto-oncogene GTPase (KRAS) wild-type (KRAS ${ }^{\mathrm{WT}}$ ) CRC, but are ineffective on KRAS mutation (KRAS ${ }^{\mathrm{MUT}}$ ) CRC (8). The Food and Drug Administration (FDA) have approved two monoclonal antibodies (cetuximab and panitumumab) that inhibit EGFR. Cetuximab is a chimeric IgGl anti-EGFR monoclonal antibody, while panitumumab is a complete human IgG2 anti-EGFR 
monoclonal antibody (9). Cetuximab and panitumumab have been demonstrated to increase the overall survival rate of CRC; however, cetuximab is $<30 \%$ effective in patients (10). Clinical data has confirmed that KRAS mutations reduce the effect of cetuximab and panitumumab, resulting in the use of these monoclonal antibodies only in patients with KRAS ${ }^{\mathrm{WT}}$ CRC (11). Identifying drugs that are effective on KRAS ${ }^{\mathrm{WT}}$ and KRAS $^{\text {MUT }}$ CRC has significance for the treatment of patients with advanced CRC.

Bioinformatics is a field of study that uses computational methods to store, retrieve and analyze biological information. It is one of the newest fields of biological research (12). Bioinformatics analysis involves the screening of large datasets from gene chips. There are a number of convenient online analytics tools (GEO2R, GCBI, DAVID, KEGG and GATHER) and analysis software (BRB-ArrayTools and Funrich) available. The present study aimed to investigate the common oncogenes of KRAS ${ }^{\mathrm{WT}}$ and $\mathrm{KRAS}^{\mathrm{MUT}}$ using bioinformatics analysis, and to perform gene function and pathway enrichment analysis. Additionally, the expression of COL1A1 in CRC tissues and cells was verified, and the association between COL1A1 and clinicopathological parameters in CRC clinical samples was analyzed.

KRAS mutation rates reached $40 \%$ in patients with CRC, as reported in 2017 (13). Identifying target genes that are effective against wild-type and mutant KRAS may aid in identifying more effective drugs for the treatment of CRC, and provide a theoretical foundation for the application of relevant targets to clinical medicine.

\section{Materials and methods}

Microarray data. The gene expression profiles from the GSE38026 dataset were used for analysis in the presents study (https://www.ncbi.nlm.nih.gov/geo/query/acc. cgi?acc=GSE38026). GSE38026 was based on the Agilent GPL11532 platform (Affymetrix Human Gene 1.1 ST Array; Affymetrix; Thermo Fisher Scientific, Inc., Waltham, MA, USA). The GSE38026 dataset contained 32 samples, including eight KRAS ${ }^{\mathrm{WT}}$ healthy control colon mucosa samples, eight KRAS ${ }^{\text {MUT }}$ healthy control colon mucosa samples, eight $\mathrm{KRAS}^{\mathrm{WT}}$ CRC samples and eight KRAS ${ }^{\mathrm{MUT}}$ CRC samples.

Tissue samples, tissue microarrays and cell lines. A total of 24 pairs of CRC tissues and adjacent non-cancerous controls were collected at Xinxiang Central Hospital (Xinxiang, China) between June 2016 and December 2016. Samples of patients with CRC were all diagnosed as primary CRC for the first time. No patients received radiotherapy, chemotherapy or biological therapy prior to surgery. The patient age range was 33-78 years old, including 9 males and 15 females. The present study was approved by Xinxiang Medical University Ethics Committee, and all patients provided written informed consent for participation in the present study. The tissue specimens were frozen in liquid nitrogen and stored at $-80^{\circ} \mathrm{C}$. When observed under a microscope, malignant glandular infiltration exceeding mucosal muscularis to the submucosa is considered to indicate colorectal adenocarcinoma, according to the World Health Organization (3). All tissues were confirmed to be adenocarcinoma. Classifications were based on the system of the International Union Against Cancer (3). Tissue chips, including 150 points samples were purchased from Shanghai Outdo Biotech Co., Ltd. (Shanghai, China). The 150 points samples included 75 cancer and 75 healthy tissues. The CRC cell lines LOVO, DLD-1, Caco2, HT29, SW620 and SW480, as well as control intestinal mucosal epithelial FHC cells used in the present study were obtained from the American Type Culture Collection (Manassas, VA, USA) and were cultured in RPMI-1640 (HyClone; GE Healthcare Life Sciences, Logan, UT, USA) supplemented with $10 \%$ fetal bovine serum (FBS) (Gibco; Thermo Fisher Scientific, Inc.) at $37^{\circ} \mathrm{C}$ with $5 \% \mathrm{CO}_{2}$. Lovo (KRAS ${ }^{\text {MUT }}$ ) was derived from a metastatic site of colon adenocarcinoma cells. SW480 (KRAS ${ }^{\text {MUT }}$ ) was established from a primary adenocarcinoma of the colon. SW620 $\left(\mathrm{KRAS}^{\mathrm{MUT}}\right.$ ) was derived from a metastasis of the same tumor from which SW480 was derived (12). DLD-1 (KRAS ${ }^{\mathrm{MUT}}$ ), Caco2 $\left(\right.$ KRAS $\left.^{\mathrm{WT}}\right)$ and HT29 (KRAS ${ }^{\mathrm{WT}}$ ) were derived from colorectal adenocarcinoma cell lines $(14,15)$.

Identification of differentially expressed genes (DEGs). Analysis was performed using GEO2R from the National Center for Biotechnology Information (16). DEGs from cancer and adjacent control tissues of KRAS ${ }^{\mathrm{WT}}$ and KRAS ${ }^{\mathrm{MUT}}$ patients were analyzed. Subsequently, the overlap between the two DEG groups representing similarly behaving genes independent of KRAS status was analyzed. DEGs were selected with a $\geq 1.2$-fold-change and $\mathrm{P}<0.05$ was considered to indicate a statistically significant difference.

Gene ontology (GO) and pathway enrichment analysis of DEGs. GO analysis is used to identify characteristic biological attributes for DEGs, and Kyoto Encyclopedia of Genes and Genomes (KEGG) pathway analysis may be used to determine which signaling pathways are associated with these DEGs. FunRich is a stand-alone software tool that supports the enrichment analysis for biological processes, cellular components, molecular functions and biological pathways (17). GO enrichment and KEGG pathway analysis were performed using the FunRich tool. $\mathrm{P}<0.05$ was considered to indicate a statistically significant difference.

Integration of the protein-protein interaction (PPI) network and module analysis. STRING (http://www.string-db.org) is a database of known and predicted PPIs. The STRING database (version 10.0) currently covers 9,643,763 proteins from 2,031 organisms (18). DEGs were mapped to STRING to analyze interactive associations among DEGs. An interaction score of $>0.4$ was considered valid. Subsequently, the network data was exported as simple tabular text and PPIs were constructed using Cytoscape software (19). A plug-in module of MCODE was used to screen for hub proteins (20). MCODE identifies clusters (highly interconnected regions) in a network. The criteria were set as follows: MCODE scores $>5$ and number of nodes $>5$.

RNA extraction and reverse transcription-quantitative polymerase chain reaction ( $R T-q P C R)$. Total RNA was extracted from tissues and cells using TRIzol reagent (Thermo Fisher Scientific, Inc.) according to the manufacturer's protocol. Total RNA was collected from 24 paired CRC tissues and adjacent 
Table I. Clinicopathological characteristics of patients with CRC for RT-qPCR.

\begin{tabular}{lc}
\hline Characteristics & Value \\
\hline Age, years & \\
Range & $33-78$ \\
Mean \pm SD & $59.25 \pm 11.61$ \\
Sex, n (\%) & \\
Male & $9(37.5)$ \\
Female & $15(62.5)$ \\
AJCC TNM classification, n (\%) & \\
I & $1(4.2)$ \\
IIA & $2(8.3)$ \\
IIB & $8(33.3)$ \\
IIIA & $5(20.8)$ \\
IIIB & $7(29.2)$ \\
IV & $1(4.2)$ \\
Lymph node metastasis, n (\%) & \\
Yes & $12(50.0)$ \\
No & $12(50.0)$ \\
Distant metastasis, n (\%) & \\
Yes & $1(4.2)$ \\
No & $23(95.8)$ \\
\hline SD, standard deviation; AJCC TNM, American Joint & Committee \\
on Cancer TNM, tumor node metastasis; CRC, colorectal cancer; \\
RT-qPCR, reverse transcription-quantitative polymerase chain reac- \\
tion. \\
\hline
\end{tabular}

control tissues, and six CRC cell lines (LOVO, DLD-1, Caco2, HT29, SW620 and SW480), as well as control intestinal mucosal epithelial FHC cells. The detailed information of 24 pair samples are presented in Table I. RNA was reverse transcribed to cDNA using a PrimeScript Reverse Transcription kit (Takara Bio, Inc., Otsu, Japan). The RT reaction mixture contained $1 \mu \mathrm{l}$ RNA (500 ng), $2 \mu 15 X$ PrimeScript Buffer, $0.5 \mu 1$ PrimeScript RT enzyme mix I, $0.5 \mu \mathrm{l}$ Oligo(dT) primer $(50 \mu \mathrm{M}), 0.5 \mu \mathrm{l}$ random hexamers $(100 \mu \mathrm{M})$ and $4.5 \mu \mathrm{l}$ RNase-free $\mathrm{ddH}_{2} \mathrm{O}$. The tubes were incubated for $37^{\circ} \mathrm{C}$ for $15 \mathrm{~min}$, followed by $85^{\circ} \mathrm{C}$ for $5 \mathrm{sec}$, and then stored at $4^{\circ} \mathrm{C}$ in the PCR instrument. qPCR analysis was performed using SYBR-Green I (Takara Bio, Inc.) and each experiment was performed in triplicate. The $\mathrm{qPCR}$ reaction mixture contained $10 \mu \mathrm{l} \mathrm{SYBR-Green} \mathrm{mix,} 0.8 \mu \mathrm{l}$ forward primer $(10 \mu \mathrm{M}), 0.8 \mu \mathrm{l}$ reverse primer $(10 \mu \mathrm{M}), 1 \mu \mathrm{l}$ cDNA and $7.4 \mu \mathrm{l}$ RNase/DNase free $\mathrm{ddH}_{2} \mathrm{O}$. The mixture was centrifuged $\left(4^{\circ} \mathrm{C}, 1,000 \mathrm{x} \mathrm{g}, 10 \mathrm{sec}\right)$ and then placed in an ABI 7500 fluorescence quantitative PCR instrument (Applied Biosystems; Thermo Fisher Scientific, Inc.). The procedures for the PCR reaction were as follows: Pre-denaturation at $95^{\circ} \mathrm{C}$ for $1 \mathrm{~min}$; denaturation at $95^{\circ} \mathrm{C}$ for $15 \mathrm{sec}$; annealing at $60^{\circ} \mathrm{C}$ for $15 \mathrm{sec}$; and extension at $72^{\circ} \mathrm{C}$ for $34 \mathrm{sec}$. Following 40 cycles, the $\mathrm{Cq}$ value of each sample was measured. Results were normalized to the expression of GAPDH as previously described (21). The sequences of the COL1A1 primers were as follows: Forward, 5'-GAGGGCCAAGACGAAGACATC-3' and reverse, 5'-CAGATCACGTCATCGCACAAC-3'. The primers were
Table II. Clinicopathological characteristics of patients with CRC for immunohistochemistry.

\begin{tabular}{lc}
\hline Characteristics & Value \\
\hline Age, years & \\
Range & $26-83$ \\
Mean \pm SD & $63.46 \pm 12.44$ \\
Sex, n $(\%)$ & \\
Male & $43(57.3)$ \\
Female & $42(42.7)$ \\
AJCC TNM classification, n $(\%)$ & \\
I & $13(17.3)$ \\
IIA & $13(17.3)$ \\
IIB & $8(10.7)$ \\
IIC & $2(2.7)$ \\
IIIB & $24(32.0)$ \\
IIIC & $6(8.0)$ \\
IVA & $6(8.0)$ \\
IVB & $3(4.0)$ \\
Lymph node metastasis, $\mathrm{n}(\%)$ & \\
Yes & \\
No & $36(48.0)$ \\
Distant metastasis, $\mathrm{n}(\%)$ & $39(52.0)$ \\
Yes & \\
No & $66(88.0)$ \\
\end{tabular}

SD, standard deviation; AJCC TNM, American Joint Committee on Cancer tumor node metastasis; CRC, colorectal cancer.

obtained from PrimerBank (PrimerBank ID 110349771c1), with an amplicon size of $140 \mathrm{bp}$. The sequences of the GAPDH primers were as follows: Forward, 5'-GACTCATGACCACAGT CCATGC-3' and reverse, 5'-AGAGGCAGGGATGATGTT CTG-3'. The $2^{-\Delta \Delta \mathrm{Cq}}$ method was used to calculate relative expression levels of COL1A1 in tissues. $\triangle \mathrm{Cq}$ was calculated as $\mathrm{Cq}(\mathrm{COL} 1 \mathrm{~A} 1)-\mathrm{Cq}(\mathrm{GAPDH})$, and $\Delta \Delta \mathrm{Cq}$ was calculated as $\Delta \mathrm{Cq}$ (Tumor)- $\Delta \mathrm{Cq}$ (Control). As previously described, GraphPad Prism 6.0 software (GraphPad Software, Inc., La Jolla, CA, USA) was used for graph construction (22).

Tissue microarrays and immunohistochemistry. Tissue microarrays were constructed and immunostaining was performed using a two-step protocol. The tissue microarray was purchased from Shanghai Outdo Biotech Co., Ltd. (catalog no. HCol-Ade150CS-01). Detailed clinicopathological data of the 75 patients is presented in Table II. The two-step immunohistochemical detection kit was purchased from Boster Biological Technology (catalog no. SV0002; Pleasanton, CA, USA). Experimental procedures were performed according to the manufacturer's protocols. COL1A1 expression was measured using the Q550IW Computerized Image system (Leica Microsystems, Ltd., Milton Keynes, UK). The images were viewed using Aperio-ImageScope 12.0 software (23). The anti-human COL1A1 antibody was purchased from Abcam (anti-rabbit; 1:1,000; catalog no. ab34710; Cambridge, MA, 
USA). The COL1A1 index was calculated as the (number of COL1A1-positive cells/total number of cells) x100\% (magnification, $\mathrm{x} 200)$ as previously described (24).

Immunohistochemistry score. The total COL1A1 immunostaining score was calculated as the sum of the percentage positivity of stained tumor cells and the staining intensity. The percentage positivity was scored $0-3: 0,<10 \% ; 1,10-30 \%$; $2,31-50 \%$; and $3,>50 \%$. The staining intensity was scored $0-3$; 0 , no staining; 1 , weakly stained; 2 , moderately stained; and 3 , strongly stained. The percentage positivity of cells and staining intensity were decided in a double-blinded manner. Then, the score of COL1A1 expression was calculated as the percentage positivity score $\mathrm{x}$ staining intensity score, which ranged between 0 and 9 . The final expression level of COL1A1 was defined as 'low' (0-4) and 'high' (5-9).

Western blotting. Total proteins were extracted from CRC cells. The cells were lysed in cold lysis buffer $(60 \mathrm{mM}$ Tris- $\mathrm{HCl}$ at $\mathrm{pH} 7.4,150 \mathrm{mM} \mathrm{NaCl}, 0.25 \%$ SDS and $1 \%$ Tergitol-type NP-40) containing $10 \mathrm{mM} \mathrm{NaF}, 1 \mathrm{mM} \mathrm{Na}_{3} \mathrm{VO}_{4}$ and complete protease inhibitor (Roche Diagnostics, Basel, Switzerland) for $30 \mathrm{~min}$ on ice, and were then centrifuged at $10,000 \mathrm{x}$ g at $4^{\circ} \mathrm{C}$ for $15 \mathrm{~min}$ as previously described (25). A bicinchoninic acid protein assay was used to determine protein concentration. A total of $45 \mu \mathrm{g}$ protein was separated on $10 \%$ SDS-PAGE, transferred onto nitrocellulose membranes and blocked with $5 \%$ skimmed milk. Subsequently, the membranes were incubated with the anti-COL1A1 primary antibody (anti-rabbit; dilution 1:500; catalog no. ab34710) overnight at $4^{\circ} \mathrm{C}$. The next day, membranes were incubated with the HRP-conjugated goat anti-rabbit secondary antibody (dilution 1:10,000; catalog no. AS014; ABclonal Biotech Co., Ltd., Woburn, MA, USA) as previously described (26). Semiquantification of proteins was performed using a Tanon GIS gel imaging system (Tanon1600; Tanon, Shanghai, China) as previously described (27).

Construction of a COL1A1 knockout cell line and transfection. shRNA targeted against COL1A1 was purchased from Shanghai GenePharma Co., Ltd. (Shanghai, China) with the following nucleotide sequence: 3'-TTGGTTTGCGATGACGTG-5'. The COL1A1 shRNA $(2 \mu \mathrm{g})$ and shRNA GFP control plasmids were transfected with Lipofectamine 2000 (catalog no. 11668019; Invitrogen; Thermo Fisher Scientific, Inc.) as previously described (26).

Cell counting kit-8 (CCK-8) assay. The CCK-8 proliferation assay kit was purchased from Nanjing KeyGen Biotech Co., Ltd. (catalog no. KGA317, Nanjing, China). The cell proliferation assay was performed over 4 days every $24 \mathrm{~h}$ with $1 \times 10^{3}$ cells/well. CCK- 8 reagent $(10 \mu \mathrm{l})$ was added to each well, and then the plate was incubated for $2 \mathrm{~h}$ at $37^{\circ} \mathrm{C}$. After that, the absorbance was measured at $450 \mathrm{~nm}$ using a Vmax microplate spectrophotometer (Molecular Devices, LLC, Sunnyvale, CA, USA) as previously described (28). All measurements were performed in quintuplicate in three separate experiments.

Cell invasion assay. Caco2 and SW480 cells were used for cell invasion assays. A Transwell filter was purchased from Corning Incorporated (Corning, NY, USA). The cells were digested with $0.25 \%$ trypsin and seeded into the Transwell upper chamber coated with Matrigel. RPMI-1640 culture medium was added to the upper chamber, while RPMI-1640 with FBS was plated into the lower chamber. After $24 \mathrm{~h}$ of culture, the Transwell chamber was removed. Following washing twice with PBS, the cells were fixed with $4 \%$ polyformaldehyde for $20 \mathrm{~min}$ at room temperature, washed twice with PBS and stained with Giemsa $(10 \mu \mathrm{g} / \mathrm{ml})$ for 20 min at room temperature. Cells that passed through the Matrigel and the micropores to the lower chamber were observed under a light microscope. Cells were counted under a light microscope (magnification, x200) and the invasion percentage was determined by dividing by the number of cells on the first day as previously described (29).

Bioinformatics analysis of COL1A1 and NEK2 expression levels. COL1A1 and NEK2 expression was analyzed in CRC tissues compared with adjacent tissues based on the Oncomine microarray dataset (https://www.oncomine.org/resource/ login.html). The genes associated with NEK2 were calculated using GEPIA (http://gepia.cancer-pku.cn/index.html).

Statistical analysis. Data were analyzed using SPSS 20.0 statistical software (IBM Corp., Armonk, NY, USA). Quantitative data are presented as the mean \pm standard deviation of at least three independent experiments. The differences between multiple groups were used analysis of variance followed by the Tukey's post hoc test, and two groups were examined using a two-tailed Student's t-test. Correlation analysis was determined using Pearson's correlation analysis. The associations between COL1A1 expression and clinicopathological characteristics were determined using the $\chi^{2}$ test. $\mathrm{P}<0.05$ was considered to indicate a statistically significant difference. $\mathrm{P}<0.05 ; \mathrm{P}<0.01$; $\mathrm{P}<0.001$.

\section{Results}

Identification of DEGs common for KRAS ${ }^{W T}$ and KRAS $S^{M U T}$ $C R C$. Paired KRAS ${ }^{\mathrm{WT}}$ cancer samples and adjacent control tissues were analyzed using GEO2R, which led to the identification of 395 upregulated DEGs. Similarly, eight paired KRAS $^{\mathrm{MUT}}$ cancer samples and adjacent control tissues were analyzed, whereby 519 upregulated DEGs were identified. The intersection of DEGs included 294 common DEGs that were independent of the KRAS genotype (Fig. 1).

GO and pathway analysis. Regarding biological processes, upregulated common DEGs exhibited enrichment for cell communication, signal transduction and cell growth (Fig. 2A). Cell component analysis revealed enrichment in cytoplasmic, extracellular and extracellular compartments (Fig. 2B). Regarding molecular function, the DEGs were enriched in metallopeptidase activity, extracellular matrix structural constituents and receptor binding (Fig. 2C). The pathway analysis revealed enhanced involvement in cell cycle, DNA replication and the WNT signaling pathway (Fig. 2D).

Hub-protein screening from the PPI network. Based on data from the STRING database, the top three hub modules that satisfied the preset criteria (MCODE score $>5$ with 


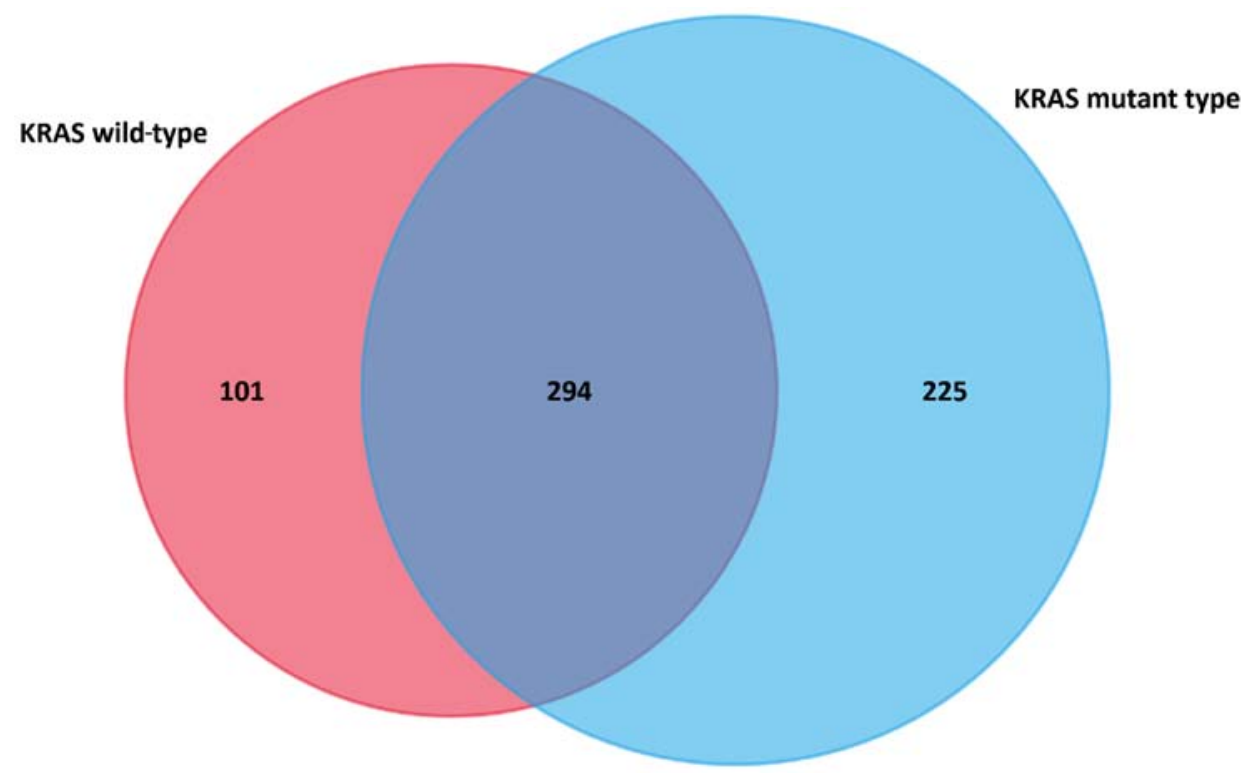

Figure 1. Venn diagram presenting upregulated genes in KRAS wild-type and KRAS mutant colorectal cancer. KRAS, KRAS proto-oncogene GTPase.

A

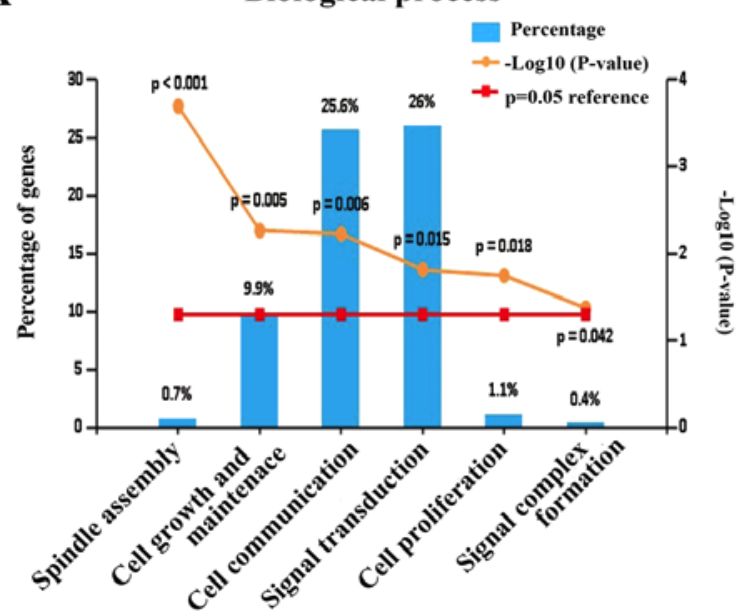

C

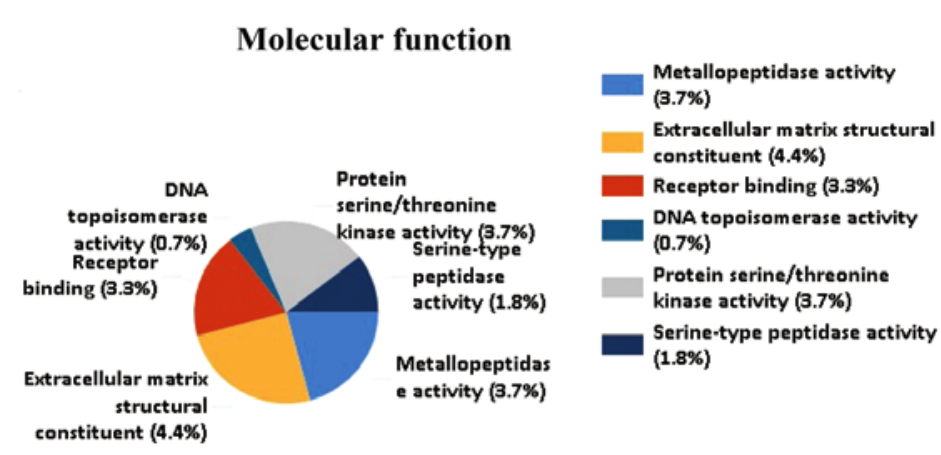

B

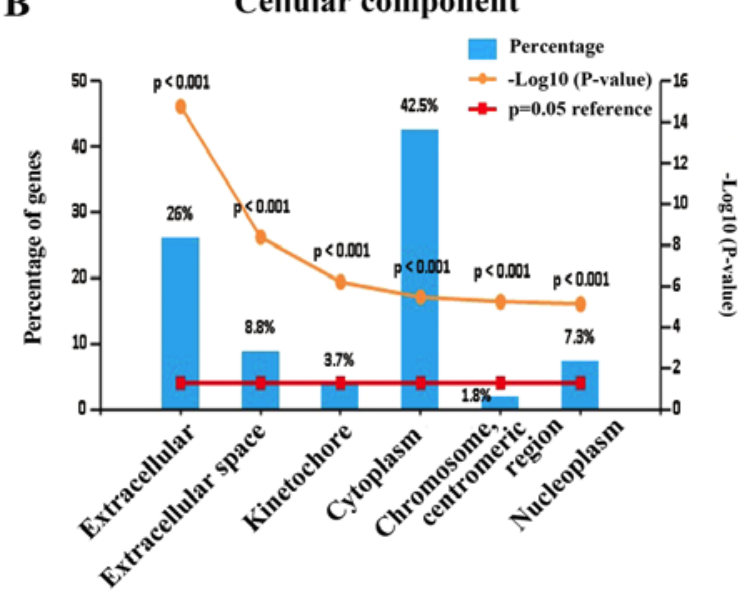

D

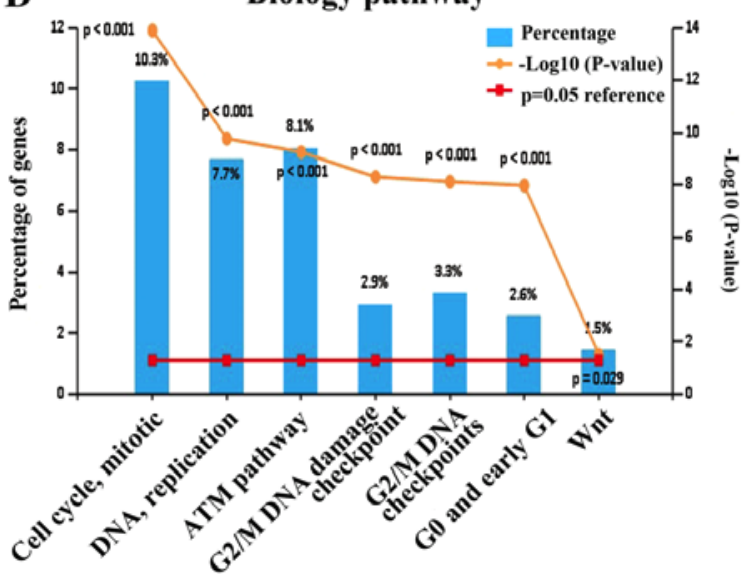

Figure 2. GO and pathway analysis of a common set of upregulated genes in CRC. (A) GO biological process analysis of DEGs in CRC. (B) GO cellular component analysis of DEGs in CRC. (C) GO molecular function analysis of DEGs in CRC. (D) GO biological pathway analysis of DEGs in CRC. GO, gene ontology; CRC, colorectal cancer; ATM, ATM serine/threonine kinase; DEGs, differentially expressed genes.

the number of nodes $>5$ ), including TPX2 microtubule nucleation factor (TPX2), NIMA related kinase 2 (NEK2) and COL1A1, were identified using Cytoscape software analysis (Fig. 3). The expression levels of COL1A1 were 


\begin{tabular}{l|l|l|}
\hline Rank & \multicolumn{1}{|c|}{ Details } \\
\hline 1 & $\begin{array}{l}\text { Score: } 8.533 \\
\text { Nodes: } 16 \\
\text { Edges: } 64\end{array}$ \\
\hline 3 & $\begin{array}{l}\text { Score: } 8.4 \\
\text { Nodes: } 21 \\
\text { Edges: } 84\end{array}$ \\
\hline & & $\begin{array}{l}\text { Score: } 7.429 \\
\text { Nodes: } 8 \\
\text { Edges: } 26\end{array}$ \\
\hline
\end{tabular}
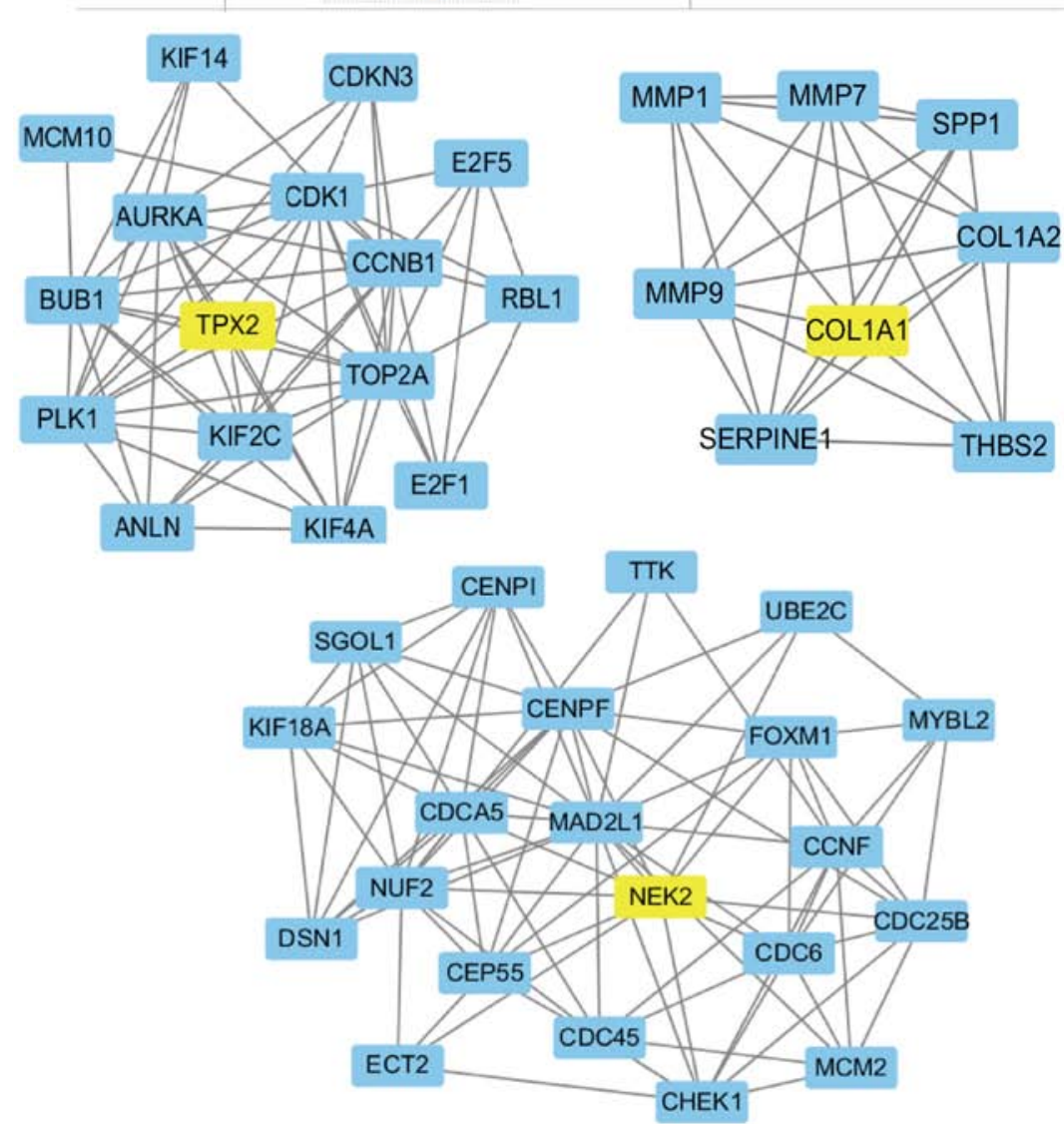

Figure 3. Three modules from the protein-protein interaction network. The hub genes are highlighted yellow. The hub gene of the first model is TPX2, the hub gene of the second model is NEK2 and the hub gene of the third model is COL1A1. TPX2, TPX2 microtubule nucleation factor; NEK2, NIMA related kinase 2; COL1A1, collagen type I $\alpha 1$.

upregulated 2.1-fold, while NEK2 was increased 1.5-fold in cancer tissues compared to healthy tissues. Drugs targeting NEK2 (Drugbank ID, DB07180; https://www.drugbank. ca/drugs/DB07180) and COL1A1 were identified using Drugbank (Drugbank ID, DB04866; https://www.drugbank. ca/drugs/DB04866), while no drugs targeting TPX2 were identified. Only one type of drug that targets NEK2 was identified and it is in the experimental phase. There are four types of drugs that target COL1A1, but only halofuginone is associated with cancer therapy and is currently in the approval process. Halofuginone is able to inhibit matrix metalloproteinase (MMP) and cell proliferation, as well as inhibit tumor matrix support, vascularization, cell invasion and cell proliferation (30). Therefore, COL1A1 and NEK2 may serve key roles in cancer development, and their target drugs may have important clinical application value.
COLIA1 mRNA is upregulated in CRC tissues and cells regardless of KRAS genotype. COL1A1 was identified to be significantly upregulated in CRC tissues compared with adjacent tissues based on the Oncomine microarray dataset, which is a web-based data-mining platform (31) (Fig. 4A). In the Oncomine database, all the CRC chip results were upregulated. Of the 11 upregulated microarray databases, The Cancer Genome Atlas (TCGA; http://cancergenome.nih.gov/) database was selected to further determine the expression patterns of COL1A1. TCGA is a powerful database platform for integration of multiple cancer genome sequencing data. This database included 19 colon specimens, three rectum specimens and 22 colorectal mucosa adenocarcinoma specimens. The results demonstrated that COL1A1 expression was upregulated 9.62-fold in CRC specimens compared with control colorectal tissue specimens. Additionally, the 
A

Disease summary for COL1A1

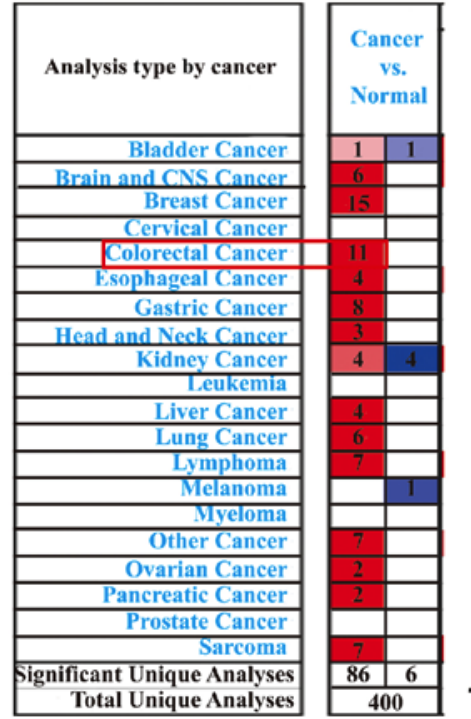

COL1A1 expression in TCGA colorectal

Colorectal mucinous adenocarcinoma vs. normal

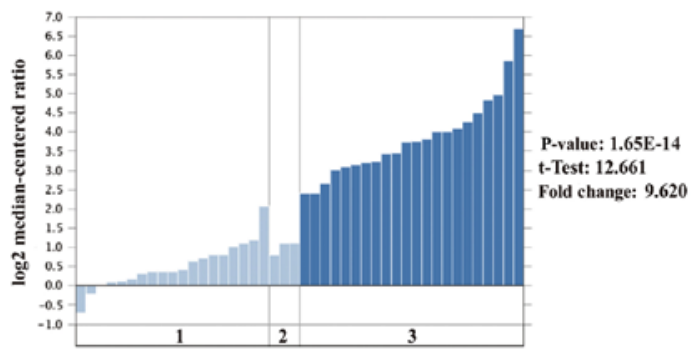

1. Colon (19) 2.Rectum (3) 3. Colorectal mucinous adenocarcinoma (22)

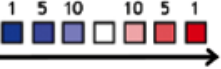

\section{B $\widehat{z}$}

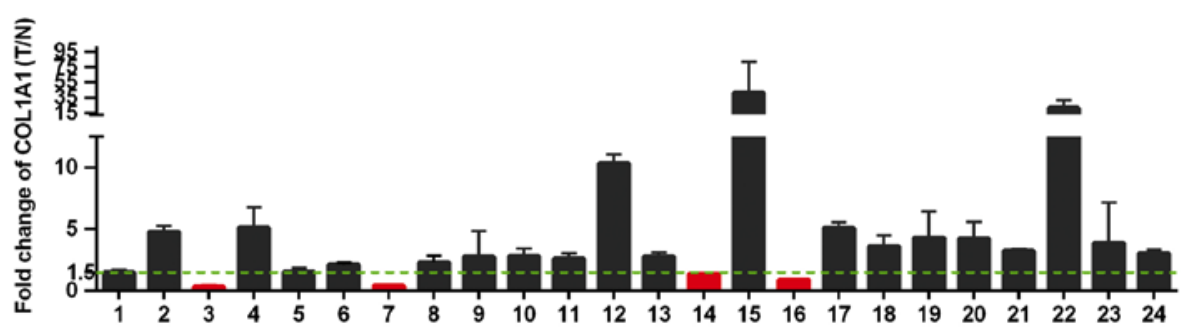

C

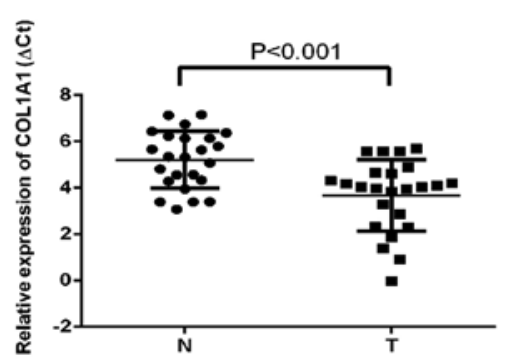

D

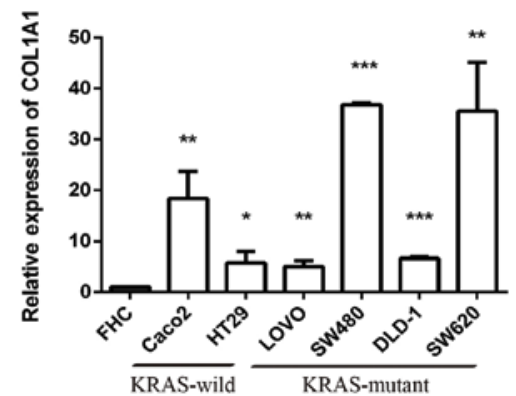

Figure 4. Expression levels of COL1A1 mRNA in CRC tissues and cell lines. (A) Expression levels of COL1A1 mRNA with CRC tissues and control tissues in Oncomine. Red boxes represent expression upregulation. The graph on the right is the results from TCGA (http://cancergenome.nih.gov/) database. TCGA is a powerful database platform for integrating multiple cancer genome sequencing data. The results showed that COL1A1 expression was upregulated 9.62-fold in CRC specimens compared with control colorectal tissue specimens. (B) RT-qPCR analysis of COL1A1 expression in 24 paired CRC tissues and adjacent control tissues. COL1A1 expression level was normalized to GAPDH and the results are presented as the fold-change in tumor tissues (T) relative to the matched adjacent healthy control tissues $(\mathrm{N})$. Error bars indicate the mean \pm standard deviation of three independent experiments. Red bars represent $\mathrm{T} / \mathrm{N}<1$. (C) The value of $\Delta \mathrm{Cq}$ was used to demonstrate the expression level of COL1A1 $(\triangle \mathrm{Cq}=\mathrm{CqCOL} 1 \mathrm{~A} 1-\mathrm{CqGAPDH})$ in the 24 paired human CRC tissues $(\mathrm{T})$ and adjacent control tissues (N) (P<0.001). (D) RT-qPCR analysis of COL1A1 expression in six CRC cell lines compared with the control colorectal epithelium FHC cell line. Error bars indicate the mean \pm standard deviation of three independent experiments. ${ }^{*} \mathrm{P}<0.05,{ }^{* *} \mathrm{P}<0.01$ and ${ }^{* * *} \mathrm{P}<0.001$. TCGA, The Cancer Genome Atlas; CRC, colorectal cancer; T, tumor tissues; N, healthy control tissues; RT-qPCR, reverse transcription-quantitative polymerase chain reaction; KRAS, KRAS proto-oncogene GTPase; COL1A1, collagen type I $\alpha 1$.

expression level of COL1A1 mRNA in tumor and non-tumor tissues from 24 patients with CRC was confirmed. RT-qPCR analysis revealed significantly higher COL1A1 mRNA expression in 20/24 CRC specimens compared with the adjacent control mucosa tissues $(\mathrm{P}<0.001$; Fig. $4 \mathrm{~B}$ and $\mathrm{C})$. The expression levels of COL1A1 mRNA were further evaluated in six $\mathrm{KRAS}^{\mathrm{WT}}$ and KRAS ${ }^{\mathrm{MUT}} \mathrm{CRC}$ cell lines, LOVO, DLD-1, Caco2, HT29, SW620 and SW480. Compared with the control colorectal epithelium FHC cells, the expression levels of COL1A1 mRNA were significantly upregulated in all investigated CRC cell lines (Fig. 4D).
COLIAl protein is upregulated in CRC tissues and cells regardless of KRAS genotype. The protein expression levels of COL1A1 in 75 paired CRC and adjacent control tissues were determined using tissue microarray. COL1A1 protein expression was significantly higher in CRC tissues compared with adjacent tissues (Fig. 5A and B). Furthermore, in order to investigate the clinicopathological significance of COL1A1, the expression of COL1A1 was divided into a high-expression group $(n=12)$ and a low-expression group $(n=12)$ based on the median COL1A1 expression level, which was 5.191489802. It was demonstrated that COL1A1 expression was positively associated with serosal 
A

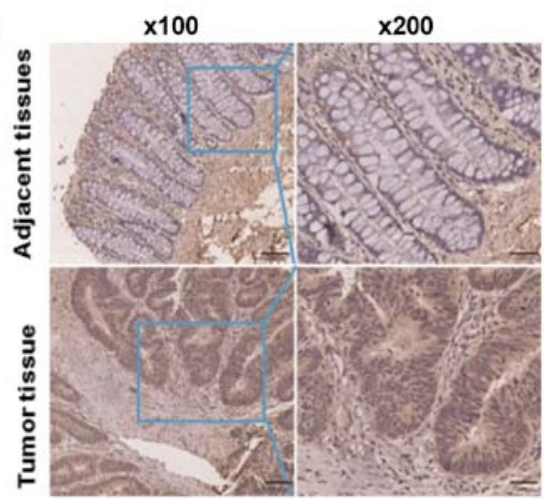

B

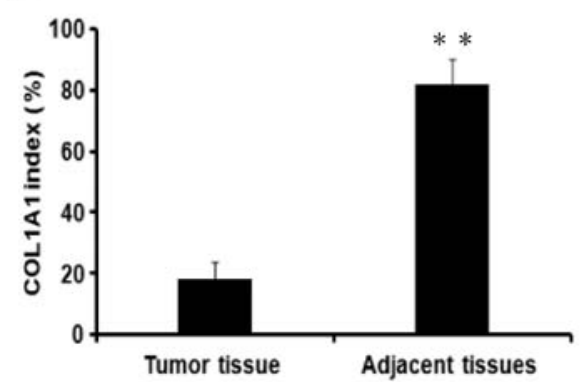

C
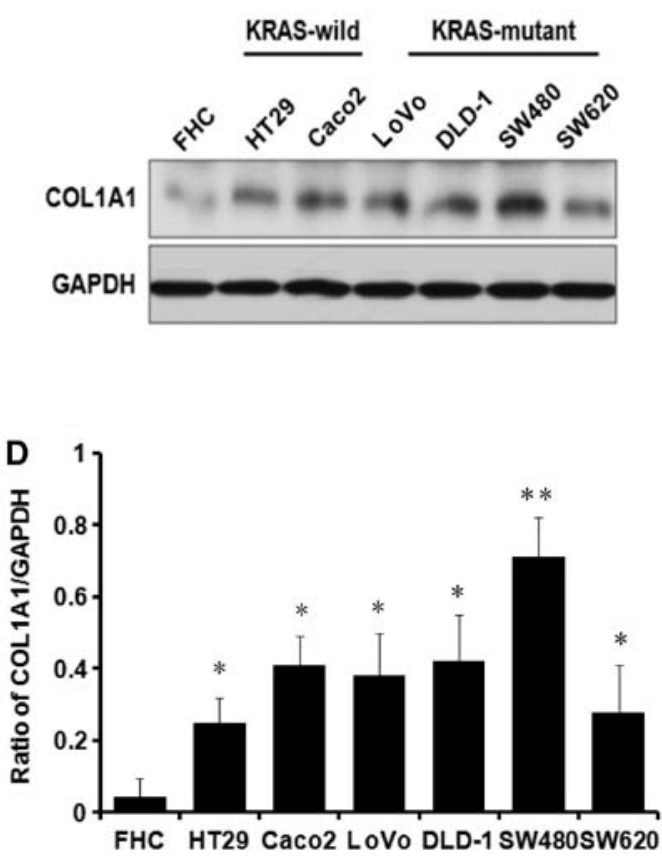

Figure 5. Expression levels of COL1A1 protein in CRC tissues and cell lines. (A) Representative immunohistochemical staining of COL1A1 in CRC specimens. Left scale bar, $200 \mu \mathrm{m}$; Right scale bar, $100 \mu \mathrm{m}$. (B) The COL1A1 index was calculated as follows: (Number of COL1A1-positive cells/number of total cells) $\mathrm{x} 100 \%$ (magnification, $\mathrm{x} 200$ ). Error bars indicate the mean \pm standard deviation of five different fields. (C) Western blot analysis of the expression of COL1A1 protein in six CRC cell lines compared with the control colorectal epithelium FHC cell line. (D) Semi-quantitative analysis of COL1A1 protein expression. Error bars indicate the mean \pm standard deviation of three independent experiments. ${ }^{*} \mathrm{P}<0.05$ and ${ }^{* *} \mathrm{P}<0.01$. CRC, colorectal cancer; KRAS, KRAS proto-oncogene GTPase; COL1A1, collagen type I $\alpha 1$.

invasion, lymph node metastasis and distant metastasis in CRC, but not with sex, age or tumor size (Table III). The expression of COL1A1 protein was also detected in CRC cell lines. The expression of COL1A1 protein was significantly upregulated in the investigated CRC cell lines compared with that in FHC cells, independent of KRAS status (Fig. 5C and D). These results indicated that the expression of COL1A1 mRNA and protein in CRC cells was increased, regardless of whether KRAS was mutated or not. Therefore, COL1A1 may be effective as a drug target for KRASMU or KRAS ${ }^{\mathrm{WT}} \mathrm{CRC}$.

Inhibition of COL1A1 suppresses proliferation and invasion in $K R A S^{W T}$ and KRAS $S^{M U T}$ CRC cell lines. Based on the obtained results, two CRC cells lines Caco2 $\left(\mathrm{KRAS}^{\mathrm{WT}}\right)$ and SW480 $\left(\mathrm{KRAS}^{\mathrm{MUT}}\right)$ were selected to explore the role of COL1A1 in cell proliferation and invasion. shRNA COL1A1 was used to inhibit the expression of the COL1A1 in the two cell lines and the efficiency of transfection was assessed by western blotting (Fig. 6A). The cell proliferation assay demonstrated that inhibition of COL1A1 significantly decreased the proliferation of Caco2 and SW480 cells (Fig. 6B and C). Proliferation decreased from the second day and was most notable on the fourth day in the two cell lines. Similarly, inhibition of COL1A1 significantly decreased the invasive abilities of Caco2 and SW480 cells by day 3 (Fig. 6D and E).

Bioinformatics analysis of NEK2 expression level and function. NEK2 was upregulated in CRC tissues compared with adjacent tissues based on the Oncomine microarray dataset. The results of the TCGA database analysis are presented in Fig. 7A. This database included 19 colon specimens, three rectum specimens and 101 colorectal mucosa adenocarcinoma specimens. The results demonstrated that NEK2 expression was upregulated 3.496-fold in CRC specimens compared with control colorectal tissue specimens. Furthermore, the results from the TCGA data revealed that NEK2 was significantly correlated with MYC proto-oncogene bHLH transcription factor (c-Myc), Cyclin D1, cluster of differentiation (CD)44 and Snail genes, but not with MMP9 or MMP2 (Fig. 7B). The data were calculated using GEPIA (http:/gepia.cancer-pku.cn/ index.html) (Fig. 7). These results suggested that NEK2 may serve a role in tumor proliferation and metastasis, but that it does not promote metastasis by dissolving matrix components.

\section{Discussion}

$\mathrm{CRC}$ is one of the most common types of malignancies, with $>1.2$ million patients being diagnosed with $\mathrm{CRC}$ and the number of mortalities exceeding 600,000 every year worldwide (32). In the United States and other Western countries, the incidence of colorectal cancer ranks third among all malignant tumors, and the mortality rate in males and in females ranks second and third, respectively (1). Surgical treatment is primarily used at the early stages; however, $\sim 80 \%$ of patients are diagnosed with colon cancer at the late stage (2).

The FDA has approved cetuximab and panitumumab for the treatment of advanced CRC. These antibodies target human EGFR (33). Initially, these targeted drugs were used in all patients with $\mathrm{CRC}$, but it was later noted that only KRAS ${ }^{\mathrm{WT}}$ patients respond well to treatment, whereas in $\mathrm{KRAS}^{\mathrm{MUT}}$ patients 
Table III. Clinicopathological characteristics of COL1A1 expression in patients with CRC.

\begin{tabular}{|c|c|c|c|c|c|}
\hline $\begin{array}{l}\text { Clinicopathological } \\
\text { variables }\end{array}$ & No. & $\begin{array}{c}\text { High } \\
\text { expression }\end{array}$ & $\begin{array}{c}\text { Low } \\
\text { expression }\end{array}$ & $\chi^{2}$ & P-value \\
\hline \multicolumn{6}{|l|}{ Age, years ${ }^{\mathrm{a}}$} \\
\hline$<63$ & 32 & 16 & 16 & 0.010 & 0.999 \\
\hline$\geq 63$ & 43 & 22 & 21 & & \\
\hline \multicolumn{6}{|l|}{ Sex } \\
\hline Male & 43 & 22 & 21 & 0.010 & 0.999 \\
\hline Female & 32 & 16 & 16 & & \\
\hline \multicolumn{6}{|l|}{ Tumor size $\left(\mathrm{cm}^{3}\right)^{\mathrm{b}}$} \\
\hline$<36.5$ & 52 & 21 & 29 & 0.250 & 0.803 \\
\hline$\geq 36.5$ & 25 & 9 & 16 & & \\
\hline \multicolumn{6}{|l|}{ Serosal invasion } \\
\hline Yes & 61 & 27 & 34 & 5.362 & 0.036 \\
\hline No & 14 & 11 & 3 & & \\
\hline \multicolumn{6}{|l|}{ Lymph metastasis } \\
\hline Yes & 39 & 15 & 24 & 4.842 & 0.038 \\
\hline No & 36 & 23 & 13 & & \\
\hline \multicolumn{6}{|l|}{ Distant metastasis } \\
\hline Yes & 9 & 1 & 8 & 6.402 & 0.014 \\
\hline No & 66 & 37 & 29 & & \\
\hline
\end{tabular}

${ }^{a}$ Grouping of age was performed according to median; ${ }^{b}$ tumor size was grouped according to median. Associations between COL1A1 expression and clinicopathological characteristics were determined using the $\chi^{2}$ test. COL1A1, collagen type I $\alpha 1$.
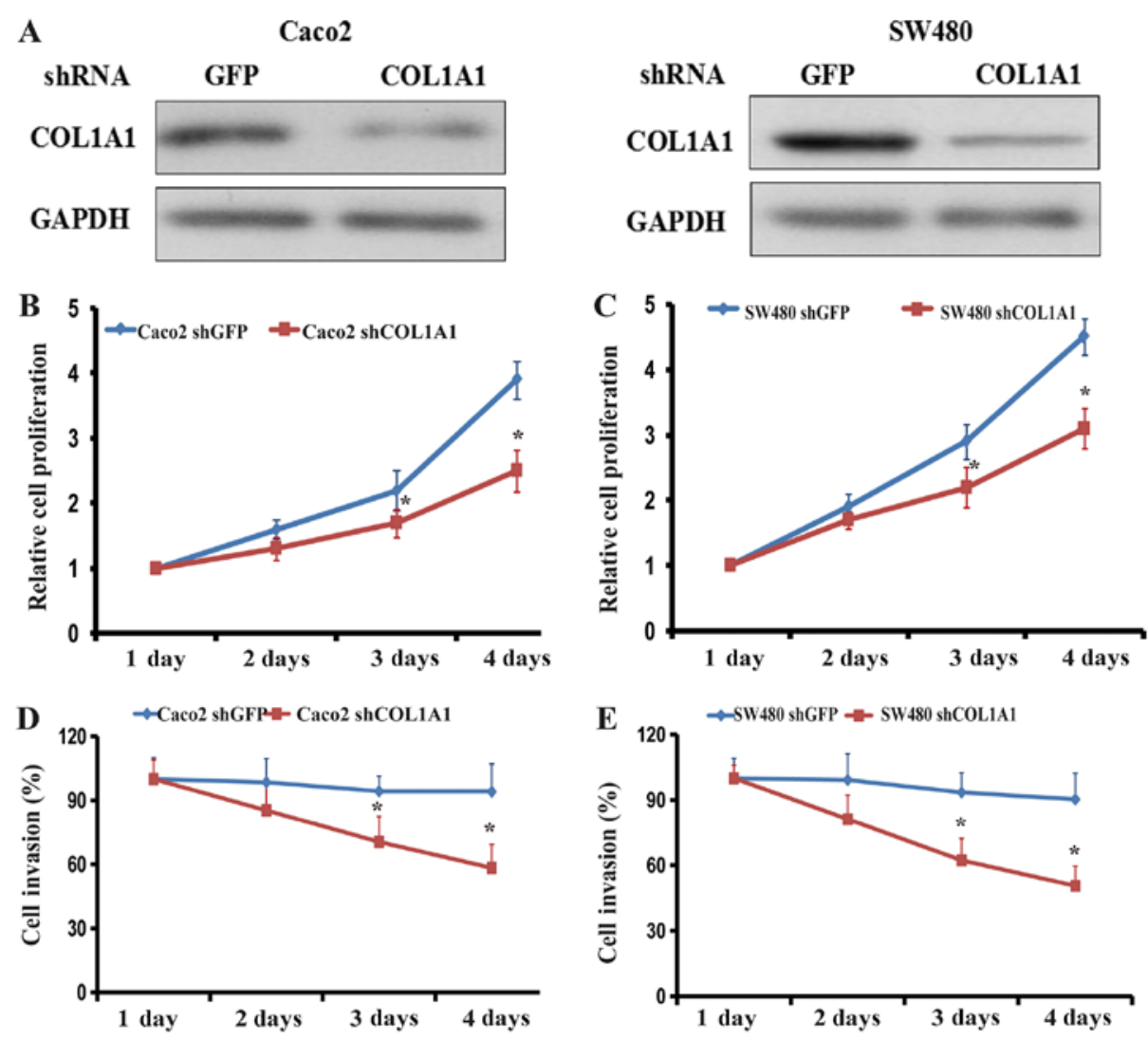

Figure 6. Inhibition of COL1A1 decreases the proliferation and invasion of CRC cells. (A) The effect of shRNA COL1A1 in Caco2 and SW480 cells. Proliferation of (B) Caco2 and (C) SW480 cells was measured using a cell counting kit-8 assay. Invasion rates of (D) Caco2 and (E) SW480 cells were analysed using a Transwell assay. Error bars indicate the mean \pm standard deviation of three independent experiments. ${ }^{*} \mathrm{P}<0.05$. COL1A1, collagen type I $\alpha 1$. 
A Disease summary for NEK2
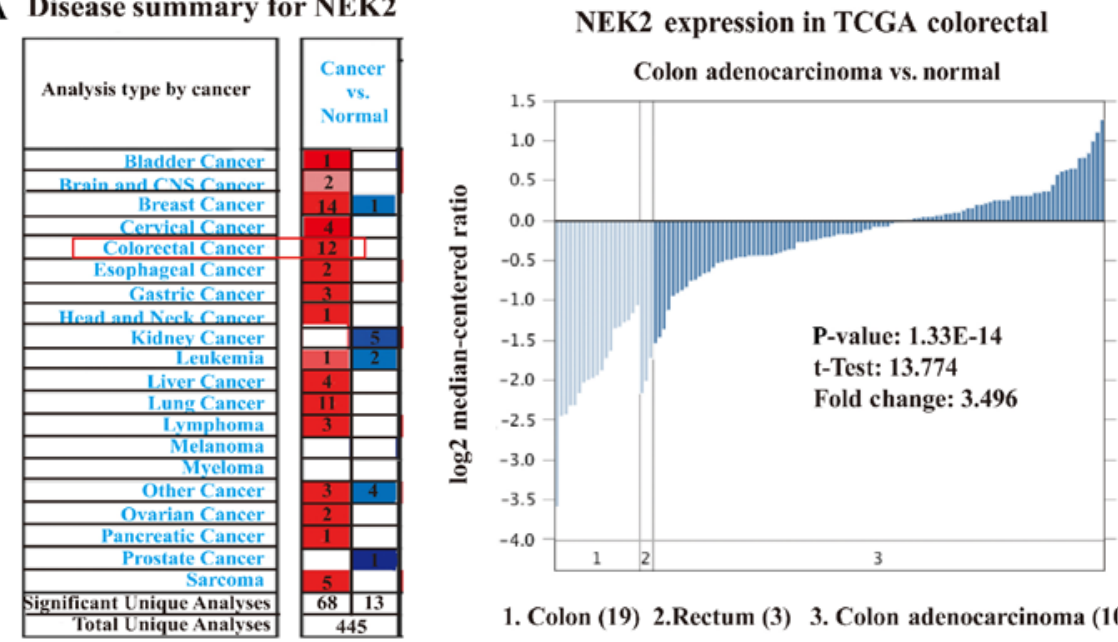

1. Colon (19) 2.Rectum (3) 3. Colon adenocarcinoma (101)
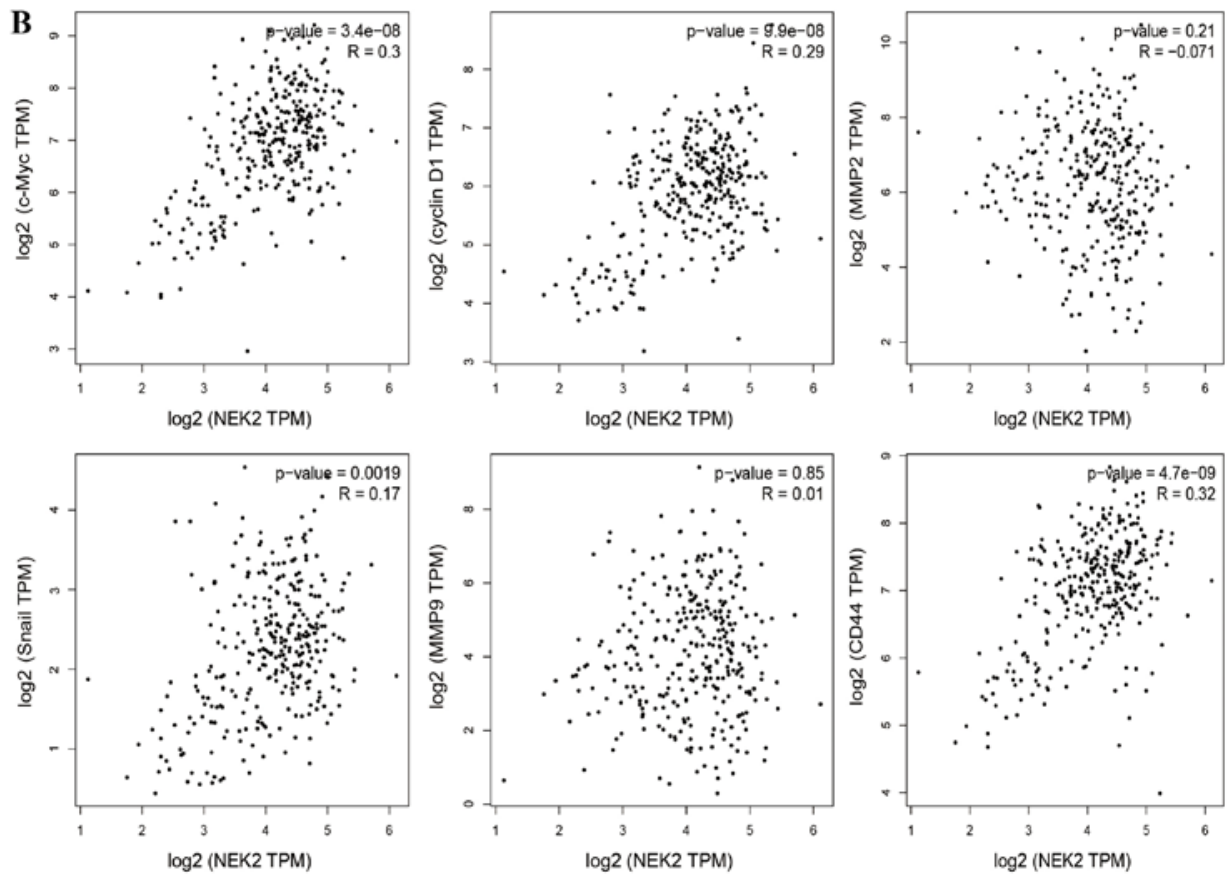

Figure 7. Bioinformatics analysis of NEK2 expression level and function. (A) Expression levels of NEK2 mRNA with CRC tissues and control tissues in Oncomine. Colour changing from blue to red indicates expression becoming stronger. The graph on the right is the results from TCGA database. The results showed that NEK2 expression was upregulated 3.496-fold in CRC specimens compared with control colorectal tissue specimens. (B) Pearson's correlation analysis of NEK2 and associated genes. We used the services provided by the website GEPIA (http://gepia.cancer-pku.cn/index.html) to examine the correlations between c-Myc, Cyclin D1, CD44, Snail, MMP9 and MMP2. CRC, colorectal cancer; KRAS, KRAS proto-oncogene GTPase; NEK2, NEK2, NIMA related kinase 2; MMP, matrix metalloproteinase; CD, cluster of differentiation; TCGA, The Cancer Genome Atlas; c-Myc, MYC proto-oncogene bHLH transcription factor; TPM, trans per million, a method for the standardization of expression values.

the application of antibodies may be not only ineffective, but also harmful (7). Since the proportion of KRAS ${ }^{\mathrm{MUT}}$ patients is $\sim 40 \%$ (34), it is important to explore novel drug targets for CRC.

In order to identify drugs targeting genes that are uniformly effective in KRAS ${ }^{\mathrm{WT}}$ and KRAS ${ }^{\mathrm{MUT}} \mathrm{CRC}$, bioinformatics techniques were used to analyze CRC samples from the GSE38026 gene expression dataset. A total of 294 commonly upregulated genes outside of the KRAS pathway were identified in the present study. These genes serve as a pool of potential uniformly effective therapy targets for CRC.

The results of GO and KEGG analyses demonstrated that the DEGs were enriched for genes involved in cell proliferation, signal transduction and tumor pathways. The PPI network analysis identified three core genes; TPX2,
NEK2 and COL1A1. The expression levels of COL1A1 and NEK2 in CRC tissues were upregulated by 2.1- and 1.5-fold compared with healthy tissues, respectively. Drugbank was also searched, and drugs specifically targeting NEK2 and COL1A1 were identified (35). The one drug targeting NEK2 is 5-[(Z)-(5-Chloro-2-oxo-1,2-dihydro-3H-indol-3-ylidene) methyl]-N,2,4-trimethyl-1H-pyrrole-3-carboxamide. This drug is currently being investigated; thus, its pharmacological effect remains unclear. There are four drugs targeting COL1A1, only the role of halofuginone has been associated with cancer treatment, and is currently in the approval process (36). Halofuginone is an effective inhibitor of COL1A1 and MMP2 gene expression, and inhibits extracellular matrix deposition and cell proliferation (36). The profound antitumor effects of 
halofuginone are attributed to its combined inhibition of tumor matrix support, vascularization, invasiveness and cell proliferation (36). COL1A1 is a major component of collagen type I, the literature associated with COL1A1 is primarily focused on osteogenesis, osteoporosis and bone diseases (37). Previously, it has been demonstrated that the COL1A1 is deregulated in a variety of tumors, including breast and gastric cancer, and that the expression of COL1A1 is higher in tumor tissues and tumor cells compared with healthy control colon mucosa samples and intestinal mucosal epithelial FHC cells, respectively (38-43).

To further confirm the results observed through bioinformatics analysis in the present study, the protein and mRNA expression levels of COL1A1 in CRC and adjacent control tissues were analyzed using immunohistochemistry and RT-qPCR, respectively. The results confirmed that COL1A1 was significantly upregulated in CRC tissue compared with adjacent tissue. No significant association was identified between COL1A1 expression and age, sex or tumor size following analysis of the clinicopathological data of patients with CRC. However, the expression was significantly associated with serosal infiltration, lymph node metastasis and hematogenous metastasis. Furthermore, the effects of COL1A1 on the growth and invasion abilities of CRC cells were assessed. The results of the functional experiments demonstrated that COL1A1 knockdown significantly reduced the proliferation and invasiveness of $\mathrm{Caco} 2$ and SW480 cells. Based on the results of our previous study, COL1A1 was demonstrated to promote CRC cell migration in vitro (26). Thus, we hypothesized that COL1A1 may be involved in the proliferation, invasion and metastasis of CRCs.

The drug target, NEK2, as a hub gene is also of interest. A previous study demonstrated that the combined treatment of NEK2 siRNA and cisplatin for CRC improved the antitumor effects of cisplatin (44). siRNAs are not widely used in clinical treatment currently; thus, drugs targeting NEK2 may be more practical at present. The expression and co-expression of NEK2 was analyzed using an online web service, GEPIA. The results demonstrated that the expression levels of NEK2 were upregulated in CRC compared with control colorectal tissue specimens. Furthermore, NEK2 expression was significantly correlated with c-Myc, Cyclin D1, CD44 and Snail gene expression, but not with MMP2 and MMP9 expression. C-Myc and Cyclin D1 are associated with tumor proliferation, CD44 and MMP9 genes are associated with tumor metastasis, and Snail is associated with epithelial-mesenchymal transition. These results suggested that NEK2 may serve a role in CRC proliferation and metastasis, but may not promote metastasis by dissolving matrix components.

In conclusion, COL1A1 and NEK2 as therapeutic gene targets may result in improved therapeutic outcomes in $\mathrm{KRAS}^{\mathrm{WT}}$ and KRAS ${ }^{\mathrm{MUT}}$ patients with CRC.

\section{Acknowledgements}

Not applicable.

\section{Funding}

The present study was supported by the Xinxiang Medical College research funding (grant nos. XYBSKYZZ201632 and
505079), Higher Education Institutions of Henan Province, China (grant no. 17A310023), The National Natural Science Foundation of China (grant no. 81702891), and Taihang Young Scholar Foundation of Xinxiang Medical University and Science and Technology Department of Henan Province, China (grant nos. 172102310651 and 122102310194).

\section{Availability of data and materials}

All data generated or analyzed during this study are included in this published article

\section{Authors' contributions}

J ZHONG and XW designed the experiments. ZZ, YW, JL, J ZHANG, CF, YZ and JY performed the experiments and analyzed the data. J ZHONG wrote the manuscript. XW revised the manuscript. All of the authors contributed to the manuscript.

\section{Ethics approval and consent to participate}

The present study was approved by Xinxiang Medical University Ethics Committee, and all patients provided written informed consent for participation in the present study.

\section{Patient consent for publication}

Not applicable.

\section{Competing interests}

The authors declare that there are no competing interests.

\section{References}

1. Siegel RL, Miller KD and Jemal A: Cancer Statistics, 2017. CA Cancer J Clin 67: 7-30, 2017.

2. Shinagawa T, Tanaka T, Nozawa H,Emoto S, MuronoK, Kaneko M, Sasaki K, Otani K, Nishikawa T, Hata K, et al: Comparison of the guidelines for colorectal cancer in Japan, the USA and Europe. Ann Gastroenterol Surg 19: 6-12, 2017.

3. Kim SG, Seo HS, Lee HH, Song KY and Park CH: Comparison of the differences in survival rates between the 7th and 8th editions of the AJCC TNM staging System for gastric adenocarcinoma: A single-institution study of 5,507 patients in Korea. J Gastric Cancer 17: 212-219, 2017.

4. Haq AI, Schneeweiss J, Kalsi V and Arya M: The Dukes staging system: A cornerstone in the clinical management of colorectal cancer. Lancet Oncol 10: 1128, 2009.

5. Laubert T, Freitag-Wolf S, Linnebacher M, König A, Vollmar B and Habermann JK; North German Tumorbank of Colorectal Cancer (ColoNet) consortium: Stage-specific frequency and prognostic significance of aneuploidy in patients with sporadic colorectal cancer - a meta-analysis and current overview. Int J Colorectal Dis 30: 1015-1028, 2015.

6. Wein A, Siebler J, Goertz R, Wolff K, Ostermeier N, Busse D, Kremer AE, Koch F, Hagel A, Farnbacher M, et al: Successful multidisciplinary treatment with secondary metastatic liver resection after downsizing by palliative second-line treatment of colorectal cancer: A Curative Option. Case Rep Oncol 9: 379-386, 2016.

7. Gherman A, Căinap C, Constantin AM, Cetean S and Căinap SS: Molecular targeted treatment of metastatic colorectal cancer: The cardiovascular adverse effects of Bevacizumab and Cetuximab. Clujul Med 90: 377-384, 2017.

8. Ohhara Y,Fukuda N, Takeuchi S, Honma R, Shimizu Y, Kinoshita I and Dosaka-Akita H: Role of targeted therapy in metastatic colorectal cancer. World J Gastrointest Oncol 8: 642-655, 2016. 
9. Gialeli Ch, Kletsas D, Mavroudis D, Kalofonos HP, Tzanakakis GN and Karamanos NK: Targeting epidermal growth factor receptor in solid tumors: Critical evaluation of the biological importance of therapeutic monoclonal antibodies. Curr Med Chem 16: 3797-3804 2009.

10. Ptashkin RN, Pagan C, Yaeger R, Middha S, Shia J, O'Rourke KP, Berger MF, Wang L, Cimera R, Wang J, et al: Chromosome 20q amplification defines a subtype of microsatellite stable, left-sided colon cancers with wild-type RAS/RAF and better overall survival. Mol Cancer Res 15: 708-713, 2017.

11. Lo Nigro C, Ricci V, Vivenza D, Granetto C, Fabozzi T, Miraglio E and Merlano MC: Prognostic and predictive biomarkers in metastatic colorectal cancer anti-EGFR therapy. World J Gastroenterol 22: 6944-6954, 2016.

12. Tao Z, Shi A, Li R, Wang Y, Wang X and Zhao J: Microarray bioinformatics in cancer - a review. J BUON 22: 838-843, 2017.

13. Sirisena ND, Deen K, Mandawala DEN, Herath $P$ and Dissanayake VH: The pattern of KRAS mutations in metastatic colorectal cancer: A retrospective audit from Sri Lanka. BMC Res Notes 10: 392, 2017.

14. Bamford S, Dawson E, Forbes S, Clements J, Pettett R, Dogan A Flanagan A, Teague J, Futreal PA, Stratton MR, et al: The COSMIC (Catalogue of Somatic Mutations in Cancer) database and website. Br J Cancer 91: 355-358, 2004.

15. Hiraoka $K$, Inoue $T$, Taylor RD, Watanabe $T$, Koshikawa $N$, Yoda H, Shinohara K, Takatori A, Sugimoto H, Maru Y, et al: Inhibition of KRAS codon 12 mutants using a novel DNA-alkylating pyrrole-imidazole polyamide conjugate. Nat Commun 6: 6706, 2015

16. Barrett T, Wilhite SE, Ledoux P, Evangelista C, Kim IF, Tomashevsky M, Marshall KA, Phillippy KH, Sherman PM, Holko M, et al: NCBI GEO: Archive for functional genomics data sets - update. Nucleic Acids Res 41: D991-D995, 2013.

17. Pathan M, Keerthikumar S, Ang CS, Gangoda L, Quek CY, Williamson NA, Mouradov D, Sieber OM, Simpson RJ, Salim A, et al: FunRich: An open access standalone functional enrichment and interaction network analysis tool. Proteomics 15: 2597-2601, 2015.

18. Geer Wallace MA and Pleil JD: Dataset of breath research manuscripts curated using PubMed search strings from 1995-2016. Data Brief 18: 1711-1724, 2018

19. Shannon P, Markiel A, Ozier O, Baliga NS, Wang JT, Ramage D, Amin N, Schwikowski B and Ideker T: Cytoscape: A software environment for integrated models of biomolecular interaction networks. Genome Res 13: 2498-2504, 2003.

20. Song E, Song W, Ren M, Xing L, Ni W, Li Y, Gong M, Zhao M, Ma X, Zhang X, et al: Identification of potential crucial genes associated with carcinogenesis of clear cell renal cell carcinoma. J Cell Biochem 119: 5163-5174, 2018.

21. Liang K, Zhou G, Zhang Q, Li J and Zhang C: Expression of hippo pathway in colorectal cancer. Saudi J Gastroenterol 20 188-194, 2014

22. Mansour RN, Enderami SE, Ardeshirylajimi A, Fooladsaz K, Fathi M and Ganji SM: Evaluation of hypoxia inducible factor-1 alpha gene expression in colorectal cancer stages of Iranian patients. J Cancer Res Ther 12: 1313-1317, 2016

23. Qasim BJ, Al-Wasiti EA and Azzal HS: Association of global DNA hypomethylation with clinicopathological variables in colonic tumors of Iraqi patients. Saudi J Gastroenterol 22: $139-147,2016$.

24. Zhang Z, Zhou C, Chang Y, Zhang Z, Hu Y, Zhang F, Lu Y, Zheng L, Zhang W, Li X, et al: Long non-coding RNA CASC11 interacts with hnRNP-K and activates the WNT/ $\beta$-catenin pathway to promote growth and metastasis in colorectal cancer. Cancer Lett 376: 62-73, 2016.

25. Zhai F, Song N, Ma J, Gong W, Tian H, Li X, Jiang C and Wang H: FGF18 inhibits MC3T3 E1 cell osteogenic differentiation via the ERK signaling pathway. Mol Med Rep 16: 4127-4132, 2017.

26. Zhang Z, Wang Y, Zhang J, Zhong J and Yang R: COL1A1 promotes metastasis in colorectal cancer by regulating the WNT/PCP pathway. Mol Med Rep 17: 5037-5042, 2018.
27. Chang Z, Shi G, Jin J, Guo H, Guo X, Luo F, Song Y and Jia X: Dual PI3K/mTOR inhibitor NVP-BEZ235-induced apoptosis of hepatocellular carcinoma cell lines is enhanced by inhibitors of autophagy. Int J Mol Med 31: 1449-1456, 2013.

28. Li S, Hu T, Yuan T, Cheng D and Yang Q: Nucleoside diphosphate kinase B promotes osteosarcoma proliferation through c-Myc. Cancer Biol Ther 19: 565-572, 2018.

29. Huang SD, Yuan Y, Zhuang CW, Li BL, Gong DJ, Wang SG, Zeng ZY and Cheng HZ: MicroRNA-98 and microRNA-214 post-transcriptionally regulate enhancer of zeste homolog 2 and inhibit migration and invasion in human esophageal squamous cell carcinoma. Mol Cancer 11: 51, 2012.

30. Biggs MB and Papin JA: Managing uncertainty in metabolic network structure and improving predictions using EnsembleFBA. PLOS Comput Biol 13: e1005413, 2017.

31. Mo CH, Gao L, Zhu XF, Wei KL, Zeng JJ, Chen G and Feng ZB: The clinicopathological significance of UBE2C in breast cancer: A study based on immunohistochemistry, microarray and RNA-sequencing data. Cancer Cell Int 17: 83, 2017.

32. Brenner H, Kloor M and Pox CP: Colorectal cancer. Lancet 383 1490-1502, 2014

33. Bertotti A, Papp E, Jones S, Adleff V, Anagnostou V, Lupo B, Sausen M, Phallen J, Hruban CA, Tokheim C, et al: The genomic landscape of response to EGFR blockade in colorectal cancer. Nature 526: 263-267, 2015.

34. Yun J, Mullarky E, Lu C, Bosch KN, Kavalier A, Rivera K, Roper J, Chio II, Giannopoulou EG, Rago C, et al: Vitamin C selectively kills KRAS and BRAF mutant colorectal cancer cells by targeting GAPDH. Science 350: 1391-1396, 2015.

35. Rask-Andersen M, Almén MS and Schiöth HB: Trends in the exploitation of novel drug targets. Nat Rev Drug Discov 10: 579-590, 2011.

36. Elkin M, Miao HQ, Nagler A, Aingorn E, Reich R, Hemo I, Dou HL, Pines $M$ and Vlodavsky I: Halofuginone: A potent inhibitor of critical steps in angiogenesis progression. FASEB J 14: 2477-2485, 2000.

37. Byers PH and Pyott SM: Recessively inherited forms of osteogenesis imperfecta. Annu Rev Genet 46: 475-497, 2012.

38. Li J, Ding Y and Li A: Identification of COL1A1 and COL1A2 as candidate prognostic factors in gastric cancer. World J Surg Oncol 14: 297, 2016

39. Song Y, Kim SH, Kim KM, Choi EK, Kim J and Seo HR: Activated hepatic stellate cells play pivotal roles in hepatocellular carcinoma cell chemoresistance and migration in multicellular tumor spheroids. Sci Rep 6: 36750, 2016.

40. Zhang H, Liu B, Xu XF, Jiang TT, Zhang XQ, Shi YL, Chen Y, Liu F, Gu J, Zhu LJ, et al: Pathophysiology of chronic pancreatitis induced by dibutyltin dichloride joint ethanol in mice. World J Gastroenterol 22: 2960-2970, 2016

41. Boguslawska J, Kedzierska H, Poplawski P, Rybicka B, Tanski Z and Piekielko-Witkowska A: Expression of genes involved in cellular adhesion and extracellular matrix remodeling correlates with poor survival of patients with renal cancer. J Urol 195: 1892-1902, 2016

42. Brooks M, Mo Q, Krasnow R, Ho PL, Lee YC, Xiao J, Kurtova A, Lerner S, Godoy G, Jian W, et al: Positive association of collagen type I with non-muscle invasive bladder cancer progression. Oncotarget 7: 82609-82619, 2016.

43. Poplawski P, Rybicka B, Boguslawska J, Rodzik K, Visser TJ, Nauman A and Piekielko-Witkowska A: Induction of type 1 iodothyronine deiodinase expression inhibits proliferation and migration of renal cancer cells. Mol Cell Endocrinol 442: 58-67, 2017.

44. Suzuki K, Kokuryo T, Senga T, Yokoyama Y, Nagino M and Hamaguchi M: Novel combination treatment for colorectal cancer using Nek2 siRNA and cisplatin. Cancer Sci 101: 1163-1169, 2010.

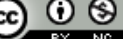

This work is licensed under a Creative Commons Attribution-NonCommercial 4.0 International (CC BY-NC 4.0) License. 